\title{
A Study on the Development the Maritime Safety Assessment Model in Korea Waterway
}

\author{
Young-Soo Park $+{ }^{+}$Jong-Sung Kim $\cdot$ Volkan Aydogdu ${ }^{* *}$ \\ * Division of Maritime Transportation System, Korea Maritime and Ocean University, Busan, 606-791, Korea \\ + Department of Ship Operation, Korea Maritime and Ocean University, Busan, 606-791, Korea \\ ** Department of Maritime Transportation and Management Engineering, Istanbul Technical University, Istanbul, Turkey
}

\begin{abstract}
Although Korea coastal area has the increasing potential marine accident due to frequent ship's encounter, increased vessel traffic and large vessel, there is no specific model to evaluate the navigating vessel's risk considering the domestic traffic situation. The maritime transport environmental assessment is necessary due to the amended maritime traffic law. However, marine safety diagnosis is now carried out by foreign model. In this paper, therefore, we suggest a domestic traffic model reflecting the characteristics of korea coastal area and navigator's risk as we named PARK(Potential Assessment of Risk) model. We can evaluate the subjective risk by establishing the model and model output into maritime risk exposure system. To evaluate this model's effectiveness, we used ship handling simulation and applied, analyzed collision accident which occurred in korea coastal area. And also, we applied integrated to an ECDIS program for monitoring traffic risk of vessels with real time based AIS data and apply to evaluate traffic risk in busan harbor waterway. As a result, we could evaluate busan harbor waterway risk effectively.
\end{abstract}

Key Words : Marine accident, PARK(Potential Assessment of Risk) model, Maritime traffic law, Vessel navigator's risk, Maritime Traffic Assessment

\section{Introduction}

The Korean has a very complicated coastlines including more than 3,200 islands and many ports along coastline. Some major ports such as Busan, Incheon, and Kwangyang are located in narrow water and surrounded with many small islands; therefore the waterways in these ports are highly congested in terms of traffic of merchant ships \& fishing vessels.

In the recent years, the in-bound and out-bound traffic has increased by $5 \%$ from 375,635 vessels in 2004 to 395,035 vessels in 2012(http://spdic.go.kr). And there are some special and specific maritime activities which restrict ship maneuvering severely such as offshore and bridge. In addition, during rainy season(summer), the visibility of the channels is severely restricted by frequent fog. As a result, the waterways \& channels are exposed to potential risks of marine accidents.

In order to reduce the risk and maritime accidents, it is important to assess quantitatively the risk of waterways and to establish a traffic safety measures based on it. According to the Marine Traffic Safety Law of Korea, which was revised in 2009, to meet the need of risk mitigation in korean waterways, Marine Traffic Safety Audit is required to secure the safe navigation, and prevent marine accidents and maximize efficiency of ports. The maritime safety audit is a formal safety diagnosis/examination method in the field of maritime traffic engineering. Existing and/or future maritime transportation must be examined by an independent audit team. The audit team systematically estimates and identifies potential risk elements associated with the development plan and offers counter measures to improve the traffic safety(Cho et al., 2010). In this process, marine traffic safety assessment is the most important part and to conduct it, the audit team is obliged to use an evaluation model.

However, the existing marine traffic safety assessment models in the literature such as the Environmental Stress Model (ES-Model), the IWRAP Model and the Formal Safety Assessment (FSA) Model have some limits when applied in the korean waterways. None of these models are korean origin and consider the risk perception of korean mariners, so that they do not satisfy the needs of maritime traffic safety assessment of korean waterways.

In order to meet the needs of marine traffic safety

\footnotetext{
* youngsoo@kmou.ac.kr, 051)410-5085

+ Corresponding author, kjsung@kmou.ac.kr, 051)410-5097
} 
A Study on the Development the Maritime Safety Assessment Model in Korea Waterway

assessment of korean waterway, it is aimed to develop a quantitative risk model, which reflects/includes risk perception of korean mariners and stakeholders. The proposed model will be the model which is the most consistent with the korean waterways. And it will be a very useful tool to establish counter-measures for mitigating risk of marine traffic in the korean waterways and to evaluate marine traffic risk of a vessel in real time.

In this paper the marine traffic environment factors are analyzed and a basic model was developed based on questionnaire survey on korean mariners. The final model was achieved by experiments with the ship-handling simulations. And then the model was used to analyze a collision accident happened in korean coastal waterway; and to integrate to an ECDIS program for monitoring traffic risk of vessels in real-time based on AIS data and was applied to evaluate traffic risk in Busan harbor waterway.

\section{Study on existing marine traffic safety assessment models}

\subsection{General}

Marine traffic safety is an important issue caused by the fast growing of shipping activities. However, number of marine traffic safety assessment models are limited Existing traffic safety assessment models and their features are summarized by Kim (2011) as given in Table 1 .

The IWRAP model has been developed to provide a standardized method of assessing the risks within most waterways. The outputs of IWRAP can be used to assess the risk in each section of a waterway and also determine the degree of risk to navigate throughout the entire waterway. The model allows engineers develop different scenarios so that proposed changes to a section of waterway can be checked and analyzed before implementation.

The risk assessment process is a disciplined approach to identify major hazards in terms of waterway safety, estimated risk levels, evaluate potential mitigation measures. And this process set the stage for implementation of selected measures to reduce risk. The PAWSA model includes gathering a selected group of waterway users/stakeholders. And this model conduct a two-day structured workshop to identify hazard, risk mitigating measures and evaluate the counter-measure in order to meet the objectives. However, the process must be carried out by joint effort of involving waterway users, stakeholders, and the agencies/entities who are responsible for implementing the selected risk mitigation measures.

The risk assessment process represents a significant part of joint public-private sector planning for risk mitigating in a waterway. When applied consistently and uniformly in a number of waterways, the process is expected to provide a basis to the best value of decisions for risk mitigation investments, both on the local and national level such as "IALA guideline to risk assessment tools.

Table 1 Existing marine traffic assessment models and their features

\begin{tabular}{|c|c|}
\hline $\mathbf{N}$ & Features \\
\hline $\begin{array}{l}\text { IWRAP } \\
\text { (IALA } \\
\text { Waterway } \\
\text { Risk } \\
\text { Assessment } \\
\text { Program) }\end{array}$ & $\begin{array}{l}\text { - Recommended by IALA(quantitative model) } \\
\text { - Calculating collision \& grounding probabilities based } \\
\text { on traffic volume/track data } \\
\text { - Theoretical explanation for calculation process is } \\
\text { limited } \\
\text { - Difficult of applying in areas where have } \\
\text { complicated traffic tracks }\end{array}$ \\
\hline $\begin{array}{c}\text { PAWSA } \\
\text { (Ports and } \\
\text { Waterways } \\
\text { Safety } \\
\text { Assessment) }\end{array}$ & $\begin{array}{l}\text { - Recommended by IALA (qualitative model) } \\
\text { - Assessment by expert group } \\
\text { - Highly depended on group members }\end{array}$ \\
\hline $\begin{array}{c}\text { ES } \\
\text { (Environment } \\
\text { Stress) }\end{array}$ & $\begin{array}{l}\text { - The most-used model in marine traffic safety in } \\
\text { Korea, Japan and Turkey } \\
\text { - Calculating maneuvering difficulties imposes by } \\
\text { surrounding environments } \\
\text { - Quantity subjective factor of mariner's stress } \\
\text { - Risk perception of Korean mariners is not reflected } \\
\text { - Risk consciousness criteria which applied are same } \\
\text { for inner and outer harbor }\end{array}$ \\
\hline $\begin{array}{c}\text { FSA } \\
\text { (Formal } \\
\text { Safety } \\
\text { Assessment) }\end{array}$ & $\begin{array}{l}\text { - Official safety assessment by IMO } \\
\text { - Various models were developed based on this model } \\
\text { such as MARA, PMSC, etc. } \\
\text { - Could be influenced by assessor's opinion }\end{array}$ \\
\hline $\begin{array}{c}\text { US } \\
\text { (Unsafe Ship } \\
\text { handling) }\end{array}$ & $\begin{array}{l}\text { - Assessment by stopping distance } \\
\text { - Ship handling simulation is the precondition } \\
\text { - Could not apply in complex traffic condition }\end{array}$ \\
\hline Others & $\begin{array}{l}\text { - Assessment by vessel encountering frequencies } \\
\text { - Assessment by give-way action frequencies } \\
\text { - Assessment by complexity of traffic routes } \\
\text { - SJ Model (Mariner's subjective awareness) } \\
\text { - BC Model (Collision awareness) } \\
\text { - Assessment models used in road traffic engineering }\end{array}$ \\
\hline
\end{tabular}




\subsection{The ES model}

The ES model expresses in quantitative terms the degree of stress imposed by topography and traffic environments on a mariner (Inoue, 2002). This model is the most-used marine traffic assessment model in Maritime Safety Audit in Korea.

Calculation of stress value in ES model is composed of the following three parts (Park et al., 2002).

(1) Evaluation of ship handling difficulty arising from restrictions on the water area available for maneuvering. A quantitative index expressing the degree of stress forced on the mariner by topographical restrictions (ES value for Land - ESL value) is calculated on the basis of the TTC (Time to Collision) with any obstacles.

(2) Evaluation of ship handling difficulty arising from restrictions on the freedom to make collision-avoidance maneuvers. A quantitative index expressing the degree of stress forced on the mariner by traffic congestion (ES value for Ship - ESS value) is calculated on the basis of the TTC with ships.

(3) Aggregate evaluation of ship handling difficulty forced by both topography and traffic environments, in which the stress value (ES value for Aggregation- ESA value) is derived by superimposing the ESL value and the ESS value in the same course.

The rank of stress can be classified according to the extent to which a dangerous situation causes a particular Subjective Judgment (SJ) value in the range of $\pm 90^{\circ}$ from the heading of ship. The stress ranking in the ES model which is set up by classifying the range of stress from 0 to 1000 is given in Fig. 1.

The ES model only consider the effect of environment(land \& ship) on 180 degrees in front of bridge so outer harbor waterway the ESA value usually very low(Negligible rank)

\begin{tabular}{|c|c|c|c|c|}
\hline SJ: & MARINERS' JDGEIENT & $\begin{array}{l}\text { ES value } \\
\Sigma[\mathrm{S} J]_{i}\end{array}$ & STRESS RANKING & $\begin{array}{l}\text { ACCEPTANCE } \\
\text { CRITERIA }\end{array}$ \\
\hline 0 & Extremely safe & $40\rfloor$ & \multirow{3}{*}{ NEGLIGIBLE } & \multirow{5}{*}{ ACCEPTABLE } \\
\hline 1 & Fairly safe & & & \\
\hline 2 & Somewhat safe & & & \\
\hline 3 & Neither safe dangerous & $\left.-4 \begin{array}{lll}5 & 0 & 0\end{array}\right)$ & & \\
\hline 4 & Somewhat dangerous & 【7 50 ○】 & MARGINAL & \\
\hline 5 & Fairly dangerous & $\left(\begin{array}{lll}9 & 0 & 0\end{array}\right)$ & CRITICAL & \multirow{2}{*}{ UNACCEPTABLE } \\
\hline 6 & Extremely dangerous & & CATASTROPHIC & \\
\hline
\end{tabular}

Fig. 1 Stress ranking and acceptance criteria

\subsection{The Formal Safety Assessment (FSA) Model}

Formal Safety Assessment is a structure and five-step systematic methodology which aims at enhancing maritime safety including protection of life, health, marine environment and property using risk analysis, cost benefit analysis and regulatory influence diagrams to facilitate decision making(MSC/Circ. 1023, MEPC/Circ. 392, 2002)

Formal Safety Assessment have following benefits;

(1) It buys as much safety as possible. Chooses options for risk control that overall give: good reduction of risk and, good value for money. Therefore it is needed to know not only a particular measure will improve safety or environmental protection but also by how much, and at what cost.

(2) Ensures the safety measures are equitable. Makes sure that securing benefit(s) for some is not unreasonably at the expense or detriment of others. Therefore it is needed to know for any particular safety or environmental protection measure: who carries the risk, who benefits from the risk reduction and who bears the cost.

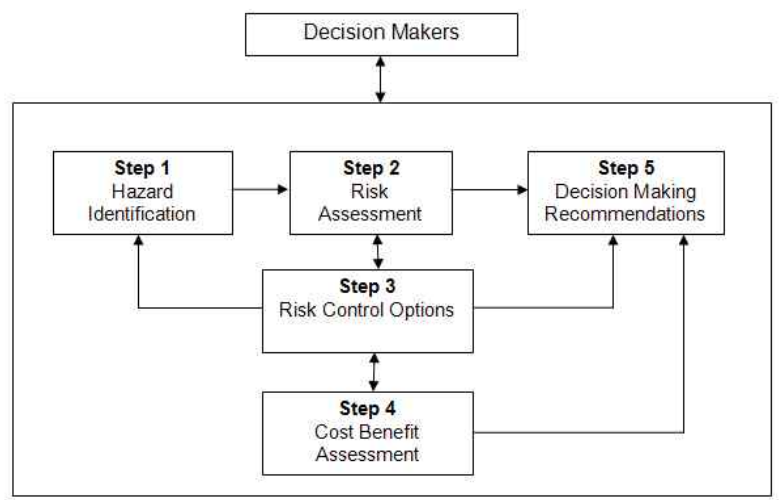

Fig. 2 The flowchart of the 5 step FSA methodology.

\subsection{Unsafe Ship handling Model}

An Unsafe Ship Handling Situation can be determined, in each time section, in terms of whether or not the Time To Collision (TTC) exceeds the Short Stopping Time (SST) under the corresponding speed. Time To Collision is calculated as the time until the ship makes contact with the obstacle or other ship on the predicted ship's path.(http://transnav2007.am.gdynia.pl)

According to the Heinrich's Law, an Unsafe Situation corresponds to the detection of some several thousand hidden unsafe situations behind one obvious case of an accident. If the appearance ratio of the proposed Unsafe Ship Handling Situation and the accident ratio in the corresponding sea area coincide with the order of $10^{-3}$, this 
A Study on the Development the Maritime Safety Assessment Model in Korea Waterway

means that, by deriving the number of Unsafe Ship Handling Situations from a series of ship-handling processes, the underlying accident risk in the process of ship handling may be estimated from the relation with this ratio of $10^{-3}$.

To verify this relationship, calibration was attempted using ship-handling simulator. In trails, several scenarios of the existing ports in Japan in which the ship encountered other ships in a curved, narrow waterway were prepared. The number of Unsafe Ship Handling Situation was counted from the results of trials, and the accident ratio was surveyed from the past records of sea casualties in the corresponding port.

The correlation between the appearance ratio of Unsafe Ship Handling Situation and the accident ratio showed reasonable coincidence with the order of $10^{-3}$.

The proposed safety evaluation index is considered to be an objective index that is unbiased towards subjectivity, and to contribute to maintaining the universality of the results on a probabilistic basis.

To verify this relationship, calibration was attempted using ship-handling simulator. In trails, several scenarios of the existing ports in Japan in which the ship encountered other ships in a curved, narrow waterway were prepared. The number of Unsafe Ship Handling Situation was counted from the results of trials, and the accident ratio was surveyed from the past records of sea casualties in the corresponding port.

The correlation between the appearance ratio of Unsafe Ship Handling Situation and the accident ratio showed reasonable coincidence with the order of $10^{-3}$.

The proposed safety evaluation index is considered to be an objective index that is unbiased towards subjectivity, and to contribute to maintaining the universality of the results on a probabilistic basis.

\section{New Safety Assessment Model development in korea waterways}

\subsection{Risk Survey of korean mariners}

The ES model is the model which is most used in korea, its coefficients are calculated based on risk perception of japanese mariners. But naturally, mariners who have different nationalities will have different risk perception. So that, it has some shortcoming when using the ES model in the korean waterway.

In this study, on the basis of vessel navigator's risk consciousness, we conducted a questionnaire survey that analyzed statistically vessel navigator's subjective risk perception which takes into account various factors such as LOA, ship's encounter situations $\left(045^{\circ}, 090^{\circ}, 135^{\circ}\right.$, overtaking, head-on, encounter direction) inside or outside harbor, relevant speed with other vessel (same, fast or slow), speed difference with other vessel and distance to other vessels as given in Fig. 3.
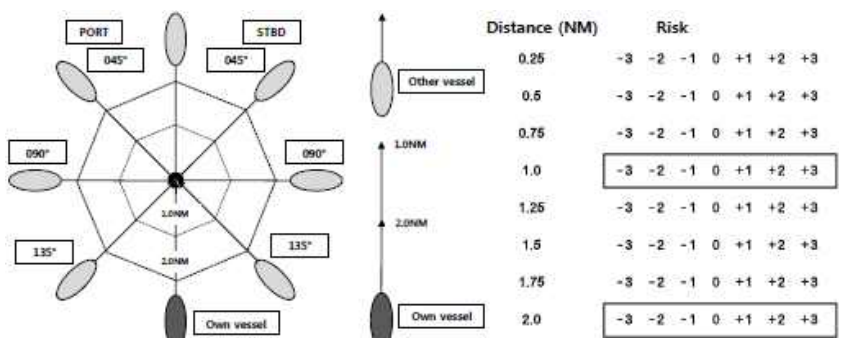

Fig. 3 Contents of questionnaire

And we also take into account some factors that influence mariner risk perception such as ship's type, ton, length, width, career, license \& position as given in Table 2 .

Table 2 Contents of questionnaire

\begin{tabular}{|l|l|}
\hline \multicolumn{1}{|c|}{ Contents } & \multicolumn{1}{|c|}{ Detail } \\
\hline $\begin{array}{l}\text { Ship on board } \\
\text { recently }\end{array}$ & (1) Kind (2) Ton (3) LOA (4) Width \\
\hline Personal data & $\begin{array}{l}\text { (1) Age (2) On board carrier (3) License (4) } \\
\text { Position }\end{array}$ \\
\hline \multirow{3}{*}{ Risk of navigation } & $\begin{array}{l}\text { 1) Record risk ranking during enter/departure } \\
\text { in port } \\
\text { (2) Record risk factor during at sea }\end{array}$ \\
\hline \multirow{2}{*}{$\begin{array}{l}\text { Record navigator's } \\
\text { risk }\end{array}$} & $\begin{array}{l}\text { Record 7 points depend on situation risk } \\
\text { Considerable dangerous, 5: a little dangerous, 4: } \\
\text { Neither safe nor dangerous, 3: a little safe, 2: } \\
\text { Considerable safe, 1: Extremely safe] }\end{array}$ \\
\hline
\end{tabular}

In the questionnaire, ships are divided into 8 types by ship types, 15 types by ships' tonnage, 14 types by length, 10 types by width, 5 types by sea experience of ship handler (career), 4 types by licenses of ship handler and 5 types by position of ship handler as given in Table 3 .

Table 3 Classification of ships' types, tonnage, length, width

\begin{tabular}{|c|c|}
\hline $\begin{array}{l}\text { Coding } \\
\text { Division }\end{array}$ & Contents \& No. \\
\hline Type & $\begin{array}{l}\text { Fishing vessel, Container, PCC, Tanker, LNG/LPG, } \\
\text { Passenger ship, Towing vessel, Other cargo vessel }\end{array}$ \\
\hline Ton & $\begin{array}{l}\text { under } \quad 500 \text { tons, } \quad 500 \sim 1,000 \text { tons, } \quad 1,000 \sim 3,000 \text { tons, } \\
3,000 \text { tons } \sim 5.000 \text { tons, } 5,000 \sim 7,000 \text { tons, } 7,000 \text { tons } \sim 10,000 \text { tons, }\end{array}$ \\
\hline
\end{tabular}




\begin{tabular}{|l|l|}
\hline \multirow{5}{*}{ Length } & $10,000 \sim 15,000$ tons, 15,000 20,000tons, 20,000 25,000tons, \\
& $25,000 \sim 30,000$ tons, 30,000 50,000tons, 50,000 60,000 tons, \\
& $60,000 \sim 75,000$ tons, 75,000 100,000tons, 100,000 tons \\
\hline \multirow{5}{*}{} & $50 \mathrm{~m} \sim 70 \mathrm{~m}, \quad 70 \mathrm{~m} \sim 90 \mathrm{~m}, \quad 90 \mathrm{~m} \sim 108 \mathrm{~m}, \quad 108 \mathrm{~m} \sim 123 \mathrm{~m}$, \\
& $123 \mathrm{~m} \sim 140 \mathrm{~m}, \quad 140 \mathrm{~m} \sim 160 \mathrm{~m}, \quad 160 \mathrm{~m} \sim 185 \mathrm{~m}, \quad 185 \mathrm{~m} \sim 205 \mathrm{~m}$, \\
& $205 \mathrm{~m} \sim 223 \mathrm{~m}, 223 \mathrm{~m} \sim 243 \mathrm{~m}, \quad 243 \mathrm{~m} \sim 259 \mathrm{~m}, \quad 259 \mathrm{~m} \sim 277 \mathrm{~m}$, \\
& $277 \mathrm{~m} \sim 293 \mathrm{~m}, \quad$ over $293 \mathrm{~m}$ \\
\hline \multirow{2}{*}{ Width } & under 10m, 10m $15 \mathrm{~m}, \quad 15 \mathrm{~m} \sim 20 \mathrm{~m}, 20 \mathrm{~m} \sim 25 \mathrm{~m}, \quad 25 \mathrm{~m} \sim 30 \mathrm{~m}$, \\
& $30 \mathrm{~m} \sim 35 \mathrm{~m}, 35 \mathrm{~m} \sim 40 \mathrm{~m}, 40 \mathrm{~m} \sim 45 \mathrm{~m}, 45 \mathrm{~m} \sim 50 \mathrm{~m}$, over $50 \mathrm{~m}$ \\
\hline
\end{tabular}

3.2 Modeling the PARK Model (Potential Assessment of RisK)

This study carried out survey and statistical analysis vessel navigator's subjective risk from ship's external conditions including vessel's encounter, speed etc. And from ship's particular condition like length, type, ton etc. through the questionnaire to develop marine traffic safety assessment model. Through analysis of the questionnaires, it is necessary to analyze various factors which affect the subjective risk. After conducting variance analysis, carrying out multiple comparison and using regression, this paper developed the PARK model as follow.

The PARK model is good for applying in waterway which has

congested traffic area \& land effect does not impose on risk value clearly. Table 4 shows estimation values of vessel navigator's subjective risk assessment for ship's external conditions as ship's encounter, speed, distance, length, approaching side and within/out harbor. And it makes following expression like equation (1). If value of variable is positive, the risk is increased and vice versa.

Table 4 Estimated Assessment Values of subjective risk for external conditions

\begin{tabular}{|c|c|c|c|c|}
\hline Parameter & Estimate & $\begin{array}{c}\text { Standard } \\
\text { Error }\end{array}$ & t-value & P-value \\
\hline Intercept & 4.9450 & 0.021505 & 229.94 & $<.0001$ \\
\hline Length & 0.0025 & $4.79 \mathrm{E}-05$ & 54.03 & $<.0001$ \\
\hline Crossing 045 & 0.4687 & 0.014484 & 32.36 & $<.0001$ \\
\hline Crossing 090 & 0.5044 & 0.014497 & 34.8 & $<.0001$ \\
\hline Crossing 135 & 0.6653 & 0.014517 & 45.83 & $<.0001$ \\
\hline Head-on situation & 0.6303 & 0.015868 & 39.73 & $<.0001$ \\
\hline Starboard & -0.0577 & 0.00903 & -6.4 & $<.0001$ \\
\hline Within harbor & 0.0610 & 0.008634 & 7.07 & $<.0001$ \\
\hline $\begin{array}{c}\text { Speed with other } \\
\text { vessel(same) }\end{array}$ & 0.1812 & 0.018506 & 9.79 & $<.0001$ \\
\hline $\begin{array}{c}\text { Speed with other } \\
\text { vessel(slow) }\end{array}$ & -0.0585 & 0.008145 & -7.19 & $<.0001$ \\
\hline $\begin{array}{c}\text { Speed difference } \\
\text { with other vessel }\end{array}$ & -0.0049 & 0.001939 & -2.54 & 0.011 \\
\hline $\begin{array}{c}\text { Distance with other } \\
\text { vessel }\end{array}$ & -0.4330 & 0.007848 & -55.18 & $<.0001$ \\
\hline
\end{tabular}

$$
\begin{aligned}
\text { Risk }= & 4.9450+0.025 \times \mathrm{LT}_{i}+0.4687 \times \mathrm{CR}_{45, i}+0.5044 \times \mathrm{CR}_{90, i}+ \\
& 0.6653 \times \mathrm{CR}_{35, i}+0.6303 \times \mathrm{HO}_{i}-0.0577 \times \mathrm{SB}_{i}+0.0610 \times \mathrm{WH}_{i}+ \\
& 0.1812 \times \mathrm{S}_{\text {same }, i}-0.0585 \times \mathrm{S}_{\text {slow, }}-0.0049 \times \mathrm{SD}_{i}-0.4330 \times \mathrm{D}_{i} \\
& \quad \text {.............................................................................. }
\end{aligned}
$$
Their value are binary value (ex. if encounter direction is CR45, CR45 will get value of 1 other ones will get value of 0)

- SB is ship side factor, SB is 1 if other ship is on starboard side and 0 if on port side

- WH is within harbor factor. WH is 1 if ship is inside harbor and 0 if outside harbor

- Ssame and Sslow: speed correlation factor. Their value are binary value

- SD is speed difference with other vessel (knots)

- D is distance to other vessel (nautical miles)

Table 5 shows the estimation values of subjective risk for ship's particular conditions using regression analysis through questionnaire (treat dummy variable about categorical data).

Table 5 Assessment Model to evaluate ship's risk for ship's particular-1

\begin{tabular}{|c|c|c|c|c|}
\hline Parameter & Estimate & SE & t-value & P-value \\
\hline Intercept & 5.1667 & 0.034 & 149.86 & $<.0001$ \\
\hline type1 & -0.0470 & 0.059 & -0.79 & 0.4269 \\
\hline type2 & -0.3371 & 0.018 & -18.44 & $<.0001$ \\
\hline type3 & -0.0510 & 0.028 & -1.8 & 0.0725 \\
\hline type4 & -0.0902 & 0.015 & -5.9 & $<.0001$ \\
\hline type5 & 0.3133 & 0.020 & 15.56 & $<.0001$ \\
\hline type6 & -1.6085 & 0.064 & -24.98 & $<.0001$ \\
\hline type7 & -0.0970 & 0.097 & -1 & 0.317 \\
\hline ton1 & 0.8916 & 0.219 & 4.07 & $<.0001$ \\
\hline ton2 & 0.0338 & 0.211 & 0.16 & 0.8726 \\
\hline ton3 & 1.8418 & 0.320 & 5.76 & $<.0001$ \\
\hline ton4 & -0.1264 & 0.046 & -2.74 & 0.0062 \\
\hline ton5 & -0.3574 & 0.052 & -6.85 & $<.0001$ \\
\hline ton6 & -0.7670 & 0.056 & -13.71 & $<.0001$ \\
\hline ton7 & -0.1209 & 0.052 & -2.33 & 0.0198 \\
\hline ton8 & -0.1601 & 0.038 & -4.2 & $<.0001$ \\
\hline ton9 & 0.1656 & 0.047 & 3.55 & 0.0004 \\
\hline ton10 & -0.1746 & 0.038 & -4.57 & $<.0001$ \\
\hline ton11 & -0.6825 & 0.032 & -21.14 & $<.0001$ \\
\hline ton12 & 0.0367 & 0.028 & 1.29 & 0.1954 \\
\hline ton13 & -0.3936 & 0.025 & -15.74 & $<.0001$ \\
\hline ton14 & 0.3060 & 0.021 & 14.44 & $<.0001$ \\
\hline length1 & -1.3875 & 0.208 & -6.66 & $<.0001$ \\
\hline length2 & -2.2272 & 0.327 & -6.82 & $<.0001$ \\
\hline length3 & -0.5515 & 0.056 & -9.85 & $<.0001$ \\
\hline length4 & -0.1579 & 0.057 & -2.77 & 0.0055 \\
\hline
\end{tabular}


A Study on the Development the Maritime Safety Assessment Model in Korea Waterway

Table 5 Assessment Model to evaluate ship's risk for ship's particular-2

\begin{tabular}{|c|c|c|c|c|}
\hline length5 & -0.1084 & 0.059 & -1.84 & 0.0658 \\
\hline length6 & 0.7481 & 0.063 & 11.92 & $<.0001$ \\
\hline length7 & -0.4815 & 0.036 & -13.23 & $<.0001$ \\
\hline length8 & -0.9243 & 0.029 & -32.2 & $<.0001$ \\
\hline length10 & 0.5714 & 0.032 & 17.93 & $<.0001$ \\
\hline length11 & 0.0521 & 0.028 & 1.86 & 0.0635 \\
\hline length12 & 0.7184 & 0.019 & 37.73 & $<.0001$ \\
\hline length13 & -0.2397 & 0.022 & -11.14 & $<.0001$ \\
\hline width1 & 0.5496 & 0.071 & 7.75 & $<.0001$ \\
\hline width2 & 0.0027 & 0.051 & 0.05 & 0.9582 \\
\hline width3 & 0.2233 & 0.044 & 5.12 & $<.0001$ \\
\hline width4 & -0.2868 & 0.043 & -6.6 & $<.0001$ \\
\hline width5 & 0.3703 & 0.040 & 9.28 & $<.0001$ \\
\hline width6 & 0.1046 & 0.031 & 3.4 & 0.0007 \\
\hline width7 & 0.2793 & 0.049 & 5.67 & $<.0001$ \\
\hline width8 & -0.2914 & 0.024 & -12.26 & $<.0001$ \\
\hline career9 & -0.0788 & 0.024 & -3.23 & 0.0012 \\
\hline career2 & -0.3128 & 0.022 & -13.96 & $<.0001$ \\
\hline career3 & -0.0534 & 0.018 & -3.02 & 0.0025 \\
\hline career4 & -0.1195 & 0.017 & -7.2 & $<.0001$ \\
\hline license1 & 0.2046 & 0.029 & 7.12 & $<.0001$ \\
\hline license2 & 0.1228 & 0.024 & 5.04 & $<.0001$ \\
\hline license3 & 0.2547 & 0.023 & 11.07 & $<.0001$ \\
\hline position1 & 0.1906 & 0.023 & 8.2 & $<.0001$ \\
\hline position2 & 0.1888 & 0.019 & 9.93 & $<.0001$ \\
\hline position3 & 0.3031 & 0.020 & 15.07 & $<.0001$ \\
\hline position4 & -0.0659 & 0.024 & -2.76 & 0.0058 \\
\hline & & & & \\
\hline
\end{tabular}

\section{Application of the PARK Model}

\subsection{Applying the PARK Model for a happened accident in korean coastal waterway}

On 14 December 2011, at around 06:24 06:26 am, a collision occurred in korean coastal waterway between the container ship "H" (68,250 tones deadweight / 5,680TEU) and the bulk carrier "P" (77,458GRT, laden with coal) as Fig.4.

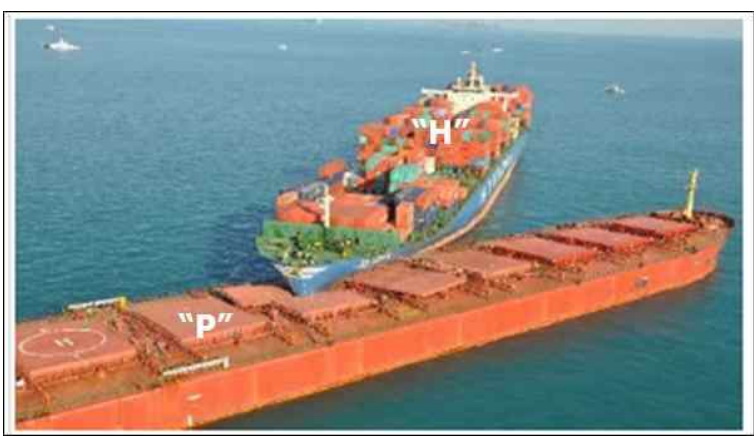

Fig. 4 Container \& Bulk carrier collision
As a consequence of the collision, the bow of " $\mathrm{H}$ " embedded in the midship section of "P", as shown in figure 3. Sea water flooded in cargo holds number 5 and 6 of the "P" and caused damage to all cargoes inside.

This study applied containership "H" \& "P" collision to PARK \& ES model respectively. Fig. 5 shows the risk of containership before distance 2 cables $(0.2$ miles $)$ before collision.

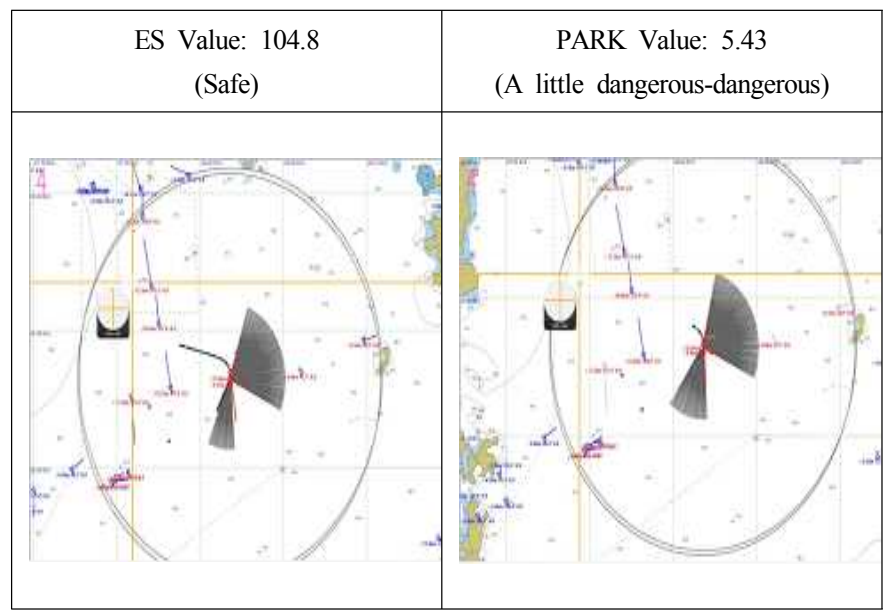

Fig. 5 Assessment Comparison before collision 2 cables between ES model and PARK model

In Fig. 5, result value of ES model presented 104.8 which means risk of this situation is negligible but the result value of PARK model shows the PARK value is 5.43 that mean it is critical situation(somewhat dangerous) According to qualified mariners, in this situation the distance of 2 cables is not enough to avoid collision. In other word, it means the collision is unavoidable. But in this situation, the ES model presents negligible while PARK model presented critical. It shows that the PARK model result is more persuasive than the ES model result.

\subsection{Display marine traffic risk of vessels in real-time}

The PARK model can also displays vessel's traffic risk in any marine traffic circumstances in real-time. Fig. 6 shows a display of an ECDIS which is integrated a module for calculating PARK values of all vessels. It will help the ship handler identify risk in each bearing toward abeam of his ship instantly. 


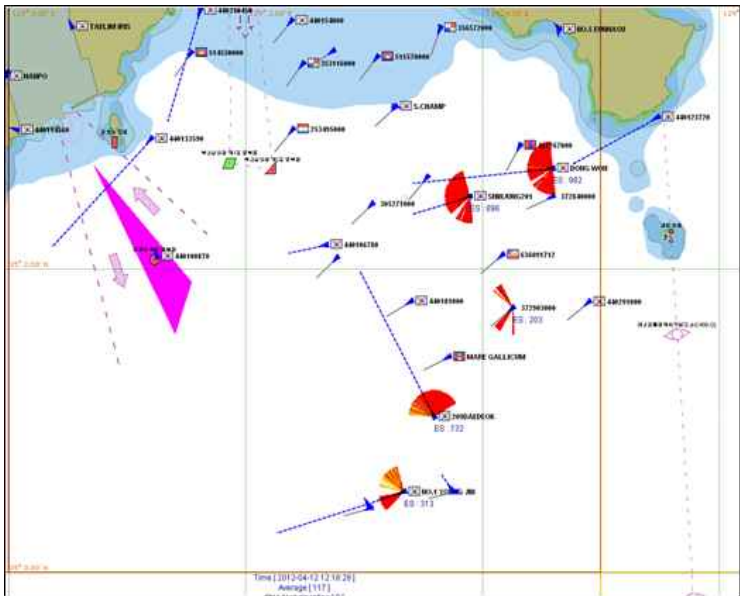

Fig. 6 Identification of risk for ship's bearing

Fig. 7 displays another application of the PARK model. It was used to assess marine traffic safety in the waterway near the Busan harbor. In Fig. 7, dangerous areas are identified based on traffic risk of passing vessels. There are many sailing vessels within \& near the Busan harbor and encountering situations are complicated so the assessment result shows that area has very high risk. And also in the southern part of Gaduk island and southwest of Busan out-harbour breakwater, the encountering situations are very complicated so we can identify those areas by seeing the dangerous risk area on the monitor.
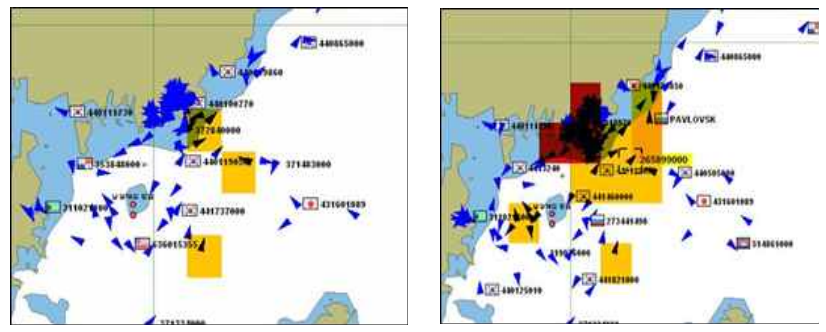

Fig. 7 Display of Dangerous areas identified by risk level of passing vessels

\section{Conclusion}

Korean coast lines are very complicated and the waterway around the major ports is narrow so the waterways are always exposed to potential risks of marine accidents. In this paper authors aimed to introduce the quantitative marine traffic risk assessment model: the Potential Assessment of RisK (PARK) model in order to monitor marine traffic and interact with fast developing dangerous traffic situations. Moreover, it is intended to carry out marine traffic risk assessment to foreseen any development. The "PARK" model can be utilized to establish maritime safety counter-measure and to determine traffic risk of vessels in real-time.

The main conclusions of this paper are as follows.

(1) This paper investigated the several kinds of traffic safety assessment models and their features. ES model is used for assessment marine traffic risk in korean coastal waterways which does not reflect Korean mariners and stake holders risk perception.

(2) In this research questionnaire survey \& statistical analysis were carried out to determine navigator's subjective risk in order to develop maritime traffic safety assessment model.

(3) The PARK Model and the ES Model were applied on a collision accident between the container ship " $\mathrm{H}$ " \& bulk carrier " $\mathrm{P}$ " which happened on 14 December 2011 in South sea. The results revealed that the PARK Model was more realistic than the ES Model.

(4) The PARK model can be used to display vessel's marine traffic risk on any marine traffic circumstances and in real time.

The PARK model can be applied to the many cases in korean waterways. It can be used to monitor fast developing undesired dangerous situation and to evaluate marine traffic safety by decision makers.

\section{Acknowledgements}

This research was a part of the project titled "Development of the Evaluation Model for the Maritime Traffic Safety" funded by the Ministry of Land, Transport and Maritime Affairs, Korea

\section{References}

[1] http://spdic.go.kr

[2] Cho I.S., Kim I.C., Lee Y.S.(2010), "The Introductory Concept of Maritime Safety Audit as a tool for Identifying Potential Hazards", Journal of Navigation and Port Research, Vol. 34, No. 9, pp. 699-704.

[3] Kim D.W.(2011), “A Primary Study on the Development of Evaluation Model for Marine Traffic Safety Assessment”, M.S. Paper, Korea Maritime University, pp. $16-41$.

[4] Inoue, Kinzo, Park, Young Soo, Usui, Hideo, Sera, Wataru and Masuda, Kenji, "Safety management of vessel traffic in ports and waterways", 30th 
A Study on the Development the Maritime Safety Assessment Model in Korea Waterway

PIANC-AIPCN Congress 2002. Sydney, N.S.W.

Institution of Engineers, 2002, 805-816.

[5] Park Y. S., Jong J. Y. and Inoue K.(2002), “A Study on Assessment of Vessel Traffic Safety Management by Marine Traffic Flow Simulation”, Journal of Korea Society of Simulation, Vol. 11, No. 4, pp. 43-55.

[6] MSC/Circ. 1023, MEPC/Circ. 392, 5th April 2002

[7] http://transnav2007.am.gdynia.pl/proceedings/pdfs/35.pdf

Received 21 November 2013

Revised 24 December 2013

Accepted 24 December 2013 